DOI: 10.17516/2782-2214-0036

УДК 664.64

\title{
PROMISING DIRECTIONS IN THE DEVELOPMENT OF NEW TYPES OF FOOD PRODUCTS USING FRUITS OF SORBUS SIBIRICA HEDL. Galina G.Pervyshina ${ }^{1 *}$, Tatiana A. Kondratyuk ${ }^{1}$, Timofey A. Khudykh ${ }^{1}$, Asiya T. Karymshakova ${ }^{1}$, Ksenia A.Valueva ${ }^{1}$, Irina S.Korotchenko ${ }^{2}$ \\ ${ }^{1}$ Siberian Federal University, Krasnoyarsk, Russian Federation \\ ${ }^{2}$ Krasnoyarsk State Agrarian University, Krasnoyarsk, Russian Federation
}

\begin{abstract}
The food industry of the Krasnoyarsk Region is highly associated with local agricultural raw materials processing, both of plant and animal origin; however, wild resources are practically not used. Moreover, food enterprises are concentrated mainly in the southern regions, while the northern regions of the region, characterized by a fairly low level of anthropogenic impact, are a promising territory for organizing the processing of plant resources, the collection of which is implemented in this area. Thus, studies aimed at substantiating the possibility of using raw plant materials from the regions of the Arctic zone of the Krasnoyarsk Territory in the production of food products are relevant. The article discusses the possibility of using fruits of Sorbus sibirica held. for the purpose of enriching food products with vitamins, minerals and dietary fibers. Current directions for the subsequent development of food products with the inclusion of wild fruits in their composition are demonstrated. A possible scheme for processing wild-growing raw materials in the area where its harvesting is implemented is given.
\end{abstract}

Keywords: fruits, Sorbus sibirica held., Krasnoyarsk Region, Arctic zone, food products, promising areas of development, organization of processing, wild plant market, enriched product, daily needs.

Citation: Pervyshina, G. G., Kondratyuk, T. A., Khudykh, T. A., Karymshakova, A. T., Valueva, K. A., Korotchenko, I. S. (2021). Promising directions in the development of new types of food products using fruits of Sorbus Sibirica Hedl. Trade, service, food industry. Vol. 1(4). Pp. 361-374.

\section{ПЕРСПЕКТИВНЫЕ НАПРАВЛЕНИЯ РАЗРАБОТКИ НОВЫХ ВИДОВ ПИЩЕВОЙ ПРОДУКЦИИ С ИСПОЛЬЗОВАНИЕМ ПЛОДОВ SORBUS SIBIRICA HEDL.}

Галина Григорьевна Первышина ${ }^{1 *}$, Татьяна Алексеевна Кондратюк ${ }^{1}$, Тимофей Алексеевич Худых ${ }^{1}$, Асия Талайбековна Карымшакова ${ }^{1}$, Ксения Александровна Валуева ${ }^{1}$, Ирина Сергеевна Коротченко

${ }^{1}$ ФГАОУ ВО «Сибирский федеральный университет», Красноярск, Российская Федерация

${ }^{2}$ ФГБОУ ВО «Красноярский государственный аграрный университет» Красноярск, Российская Федерация

\begin{abstract}
Аннотация. Пищевая промышленность Красноярского края преимущественно связана с переработкой местного сельскохозяйственного сырья растительного и животного происхождения, однако при этом практически не используются дикорастущие ресурсы. Кроме того, пищевые предприятия сосредоточены в основном на юге, в то время как северные районы края, характеризующиеся достаточно низким
\end{abstract}

(c) Siberian Federal University. All rights reserved

*Corresponding author E-mail address: eva_apple@mail.ru 
уровнем антропогенного воздействия, являются перспективной территорией для организации переработки дикоросов, сбор которых налажен в данной местности. Таким образом, актуальны исследования, направленные на обоснование возможности использования растительного сырья регионов арктической зоны Красноярского края при производстве пищевых продуктов. В статье рассмотрены вопросы применения плодов рябины сибирской с целью обогащения пищевых продуктов витаминами, минеральными веществами и пищевыми волокнами. Показаны актуальные направления для последующих разработок пищевых продуктов с включением в их состав дикорастущих плодов. Приведена возможная схема переработки сырья в условиях местности, где ведется его заготовка.

Ключевые слова: рябина сибирская, Красноярский край, арктическая зона, пищевые продукты, организация переработки, рынок дикоросов, обогащенный продукт.

Введение. В настоящее время отмечен спрос потребителей на пищевые изделия с добавлением дикорастущего съедобного сырья, которое служит перспективным источником обогащения продуктов биологически активными, минеральными веществами, витаминами, пищевыми волокнами и т. д. [1]. К сожалению, из-за суровых климатических условий сбор и переработка такого вида сырья традиционно рассматриваются только применительно к южным и центральным районам Красноярского края, в то время как главное преимущество плодов, собранных на территориях Крайнего Севера, - их произрастание в условиях экологически чистой арктической зоны (без существенного антропогенного воздействия на окружающую среду). К достаточно зимостойким видам, способным выдерживать низкие температуры (до $-45-50{ }^{\circ} \mathrm{C}$ ), ареал которых доходит до границы северного полюса, относится рябина сибирская (Sorbus aucuparia L. Subsp. Sibirica (Hedl.) Kryl.) - Sorbus Sibirica Hedl.), которую ряд авторов признает как подвид рябины обыкновенной $[2,3]$.

Целью настоящей работы стала оценка возможности использования плодов рябины обыкновенной в качестве биологически активного компонента пищевых продуктов и выявление перспективных направлений разработки новых видов пищевой продукции.

Для достижения данной цели были рассмотрены следующие задачи:

- анализ (по данным литературных источников) химического состава плодов рябины сибирской,

- оценка степени удовлетворения потребности организма человека в основных пищевых веществах в случае использования плодов рябины сибирской как обогатителя пищевой продукции,

- аналитический обзор имеющихся разработок в области использования плодов рябины обыкновенной,

- оценка ассортимента продукции, производимой с добавлением плодов рябины обыкновенной,

- выявление перспективных направлений разработки новых видов пищевой продукции, сибирской.

- формирование предложений по комплексной переработке плодов рябины

Материалы и методы. Основу исследования составляет анализ литературных источников по вопросам изучения химического состава плодов рябины сибирской [2-8, 10-15], разработанных рецептур и технологий (технологических схем) приготовления пищевой продукции с добавлением плодов рябины обыкновенной [21-36] с целью 
определения перспективных направлений разработки новых видов пищевой продукции и разработки варианта рациональной схемы переработки плодов рябины сибирской.

Обсуждение. Выбор плодов рябины сибирской в качестве обогатителя пищевых продуктов обусловлен не только широким распространением данного растения на территории Красноярского края, но и достаточно уникальным химическим составом [4-15]. Плоды рябины сибирской относят к поливитаминному сырью вследствие содержания в них достаточно широкого спектра витаминов - витамина С (200-400 мг\%), каротиноидов (провитамина А - 20-27 мг\%), витамина Р (до 2600 мг\%), группы витаминов В (витамина $\mathrm{B}_{1}$ до 0,05 мг\%, витамина $\mathrm{B}_{2}$ до 0,02 мг\%), витамина РР (до 0,05 мг\%), имеются сведения о содержании в плодах и витамина Е. Кроме того, в них присутствует достаточно широкий спектр углеводов, представленных как моносахаридами (глюкоза, галактоза, фруктоза) и дисахаридами (сахарозы), так и полисахаридами (клетчатка или целлюлоза, пектиновые вещества). Исследователями [6] зарегистрировано и присутствие многоатомных спиртов, таких как инозит и сорбит.

Минеральный состав дикорастущих плодов рябины сибирской характеризуется, с точки зрения авторов публикаций [7, 8], наличием ряда макро- (натрий, калий, кальций, фосфор, магний) и микроэлементов (железо, цинк, марганец, кобальт, молибден, алюминий, барий, ванадий, селен). В тоже время отмечена способность растительного сырья накапливать тяжелые металлы, такие как свинец, медь, кадмий, никель, хром, что свидетельствует о необходимости предварительного определения качества дикорастущего растительного сырья с целью его последующего применения в пищевых продуктах, поскольку ранее [9] была показана возможность миграции тяжелых металлов в системе почва $\rightarrow$ растительное сырье $\rightarrow$ товарный продукт.

Дополнительно следует отметить, что плоды рябины сибирской служат источником антиоксидантов, которые способны предотвратить вредное воздействие пероксидов, свободных радикалов и других веществ на организм человека. К антиоксидантам исследователи относят в первую очередь полифенолы [10], фенольные кислоты [11,12], кверцитин [13], дубильные вещества [14], тритерепноиды [15].

В табл. 1 представлены сводные данные по химическому составу плодов рябины сибирской с точки зрения оценки степени удовлетворения потребности организма человека в основных пищевых веществах

Таблица 1. Оценка степени удовлетворения потребности организма человека в основных пищевых веществах

Table 1. Assessment of the degree of satisfaction of human needs for basic nutrients

\begin{tabular}{|c|c|c|c|}
\hline $\begin{array}{l}\text { Основные } \\
\text { пищевые } \\
\text { вещества }\end{array}$ & $\begin{array}{c}\text { Содержание } \\
\text { основных пищевых } \\
\text { веществ в продукте, } \\
100 \text { г [4-16] }\end{array}$ & $\begin{array}{c}\text { Рекомендуемый } \\
\text { уровень суточного } \\
\text { потребления [17] }\end{array}$ & $\begin{array}{c}\text { Степень } \\
\text { удовлетворения } \\
\text { потребности в } \\
\text { основных пищевых } \\
\text { веществах, \% }\end{array}$ \\
\hline $\begin{array}{l}\text { Энергетическая } \\
\text { ценность, } \\
\text { кДж/ккал }\end{array}$ & $210 / 50$ & $10467 / 2500^{1}$ & 2,00 \\
\hline Белки, г & 1,4 & 75 & 1,87 \\
\hline Жиры, г & 0,2 & 83 & 0,24 \\
\hline $\begin{array}{l}\text { Усвояемые } \\
\text { углеводы, г, } \\
\text { в том числе, } \\
\text { сахар } \\
\text { (сахароза), г }\end{array}$ & 9,60 & 365 & 2,63 \\
\hline
\end{tabular}




\begin{tabular}{|c|c|c|c|}
\hline $\begin{array}{l}\text { Пищевые } \\
\text { волокна, г }\end{array}$ & 5,4 & 25 & 21,6 \\
\hline \multicolumn{4}{|c|}{ Минеральные вещества: } \\
\hline Кальций, мг & 41 & 1000 & 4,1 \\
\hline Фосфор, мг & 18 & 700 & 2,6 \\
\hline Железо, мг ${ }^{7}$ & 2 & $10 / 18$ & $20,0 / 11,1$ \\
\hline Магний, мг & 34 & 420 & 8,1 \\
\hline Цинк, мГ & 8,64 & 12 & 72,0 \\
\hline Калий, мг & 235 & 3500 & 6,7 \\
\hline Селен, мг ${ }^{7}$ & 0,14 & $0,07 / 0,055$ & $200 / 254,5$ \\
\hline \multicolumn{4}{|l|}{ Витамины: } \\
\hline $\begin{array}{l}\text { Витамин А, } \\
\text { мкг рет. экв. }\end{array}$ & $1500-1600$ & $900 / 800$ & $\begin{array}{c}166,7-177,8 / 187,5- \\
200,0 \\
\end{array}$ \\
\hline $\begin{array}{l}\text { Витамин Е ( } \alpha- \\
\text { токоферол), } \\
\text { мг ток. экв. }\end{array}$ & 1,4 & 15 & 9,3 \\
\hline Витамин C, мг & 70,0 & 100 & 70,0 \\
\hline Тиамин, мг & 0,05 & $\begin{array}{c}1,5 \text { (0,6 мг/1000 } \\
\text { ккал) }\end{array}$ & 3,3 \\
\hline $\begin{array}{l}\text { Рибофлавин, } \\
\text { мг }\end{array}$ & 0,025 & $\begin{array}{c}1,8 \text { (0,75мг/1000 } \\
\text { ккал) }\end{array}$ & 1,4 \\
\hline $\begin{array}{l}\text { Ниацин, } \\
\text { мг ниац. экв. }\end{array}$ & 0,51 & $\begin{array}{c}20 \text { (8 мг ниац. } \\
\text { экв./1000 ккал) }\end{array}$ & 2,6 \\
\hline
\end{tabular}

${ }^{\mathrm{B}}$ В числителе указаны нормы для мужчин, а в знаменателе для женщин.

Таким образом, введение плодов рябины сибирской в пищевые продукты обусловлено высоким содержанием как витаминов, в частности витамина $\mathrm{C}$ и группы каротиноидов, так и углеводов (в первую очередь пищевых волокон и пектиновых веществ), флавоноидов, макро- и микроэлементов (селена) [18-20]. Стоит отметить, что химический состав плодов в значительной степени варьируется в зависимости от абиотических (климатические и метеорологические условия) и антропогенных факторов, то есть значительную роль играет место и условия произрастания растения. Нивелировать воздействие антропогенных факторов можно, осуществляя сбор растительного сырья на территории, значительно удаленной от техносферы. Применительно к Красноярскому краю это территория арктической зоны.

Введение плодов рябины обыкновенной в рацион питания жителей Красноярского края способствует удовлетворению потребностей в витаминах А и $\mathrm{C}$, a также микроэлементов, нивелируя негативное воздействие окружающей среды, характеризуемой повышенной экологической нагрузкой как вследствие проживания значительной части населения на урбанизированных территориях, так и в сложных климатических зонах.

Конечно, исследователи неоднократно обращали внимание на возможность использования плодов рябины обыкновенной при производстве пищевых продуктов. В табл. 2 представлен перечень возможных потребительских товаров, включающих в свой состав плоды рябины сибирской или рябины обыкновенной. 
Таблица 2. Перечень возможных потребительских товаров, включающих в свой состав плоды рябины сибирской (обыкновенной) Table 2. The list of possible consumer goods from the fruits of Sorbus Sibirica Hedl.

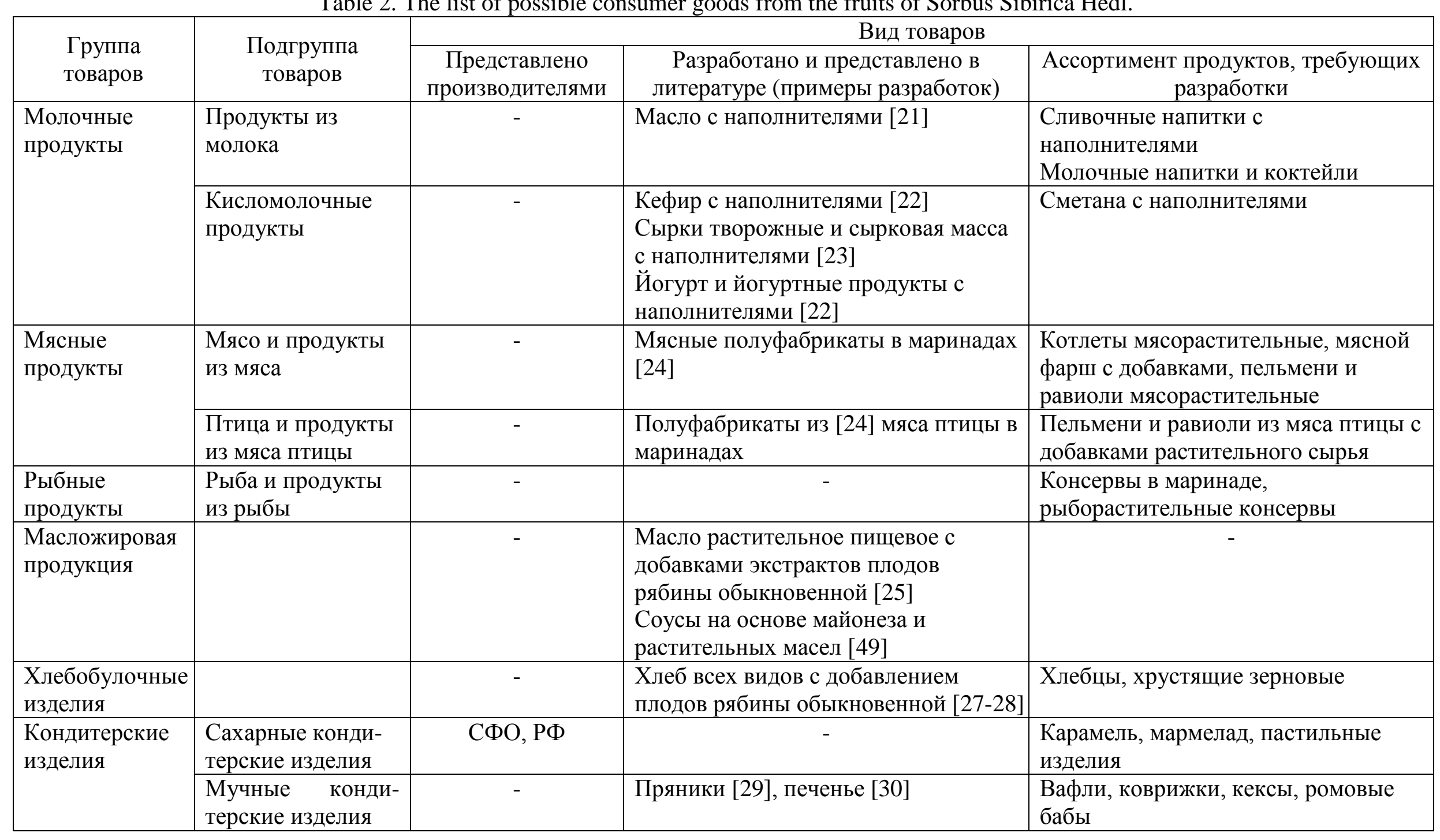




\begin{tabular}{|c|c|c|c|c|}
\hline \multirow[t]{3}{*}{$\begin{array}{l}\text { Бакалейные } \\
\text { товары }\end{array}$} & $\begin{array}{l}\text { Мука и } \\
\text { полуфабрикаты } \\
\text { мучных изделий }\end{array}$ & - & - & $\begin{array}{l}\text { Полуфабрикаты мучных изделий и } \\
\text { кондитерских изделий }\end{array}$ \\
\hline & $\begin{array}{l}\text { Крупяные и } \\
\text { бобовые изделия }\end{array}$ & - & - & Завтраки сухие \\
\hline & $\begin{array}{l}\text { Макаронные } \\
\text { изделия }\end{array}$ & - & $\begin{array}{l}\text { Макаронные изделия с добавлением } \\
\text { муки плодов рябины обыкновенной } \\
\text { [31] }\end{array}$ & - \\
\hline \begin{tabular}{l|} 
Безалкогольные \\
напитки
\end{tabular} & & - & $\begin{array}{l}\text { Безалкогольные напитки } \\
\text { газированные, негазированные, на } \\
\text { натуральных плодово-ягодных } \\
\text { соках, экстрактах и сиропах, } \\
\text { растительном сырье [33] }\end{array}$ & Соки фруктовые купажированные \\
\hline \multirow[t]{2}{*}{$\begin{array}{l}\text { Плодоовощная } \\
\text { продукция }\end{array}$} & $\begin{array}{l}\text { Фрукты: плодово- } \\
\text { ягодные консервы }\end{array}$ & $\begin{array}{c}\text { Республика } \\
\text { Беларусь, } \\
\text { Красноярский } \\
\text { край, СФО, РФ }\end{array}$ & $\begin{array}{l}\text { Конфитюр, желе, пюре, пасты, } \\
\text { сиропы }[35,36]\end{array}$ & $\begin{array}{l}\text { Компоты из дикорастущих ягод, } \\
\text { экстракты и сиропы плодово- } \\
\text { ягодные, варенье, джем, повидло }\end{array}$ \\
\hline & $\begin{array}{l}\text { Фрукты: } \\
\text { быстрозаморожен } \\
\text { ная продукция }\end{array}$ & СФО, РФ & - & - \\
\hline
\end{tabular}


Данные табл. 2 свидетельствуют о том, что несмотря на наличие достаточно большого количества разработанных исследователями видов товаров, фиксируется их отсутствие на полках торговых сетей. Анализ представленных на рынке продуктов, включающих в свой состав плоды рябины, продемонстрировал крайне низкое разнообразие последних. На рис. 1 представлены группы товаров, включающих в свой состав плоды рябины.

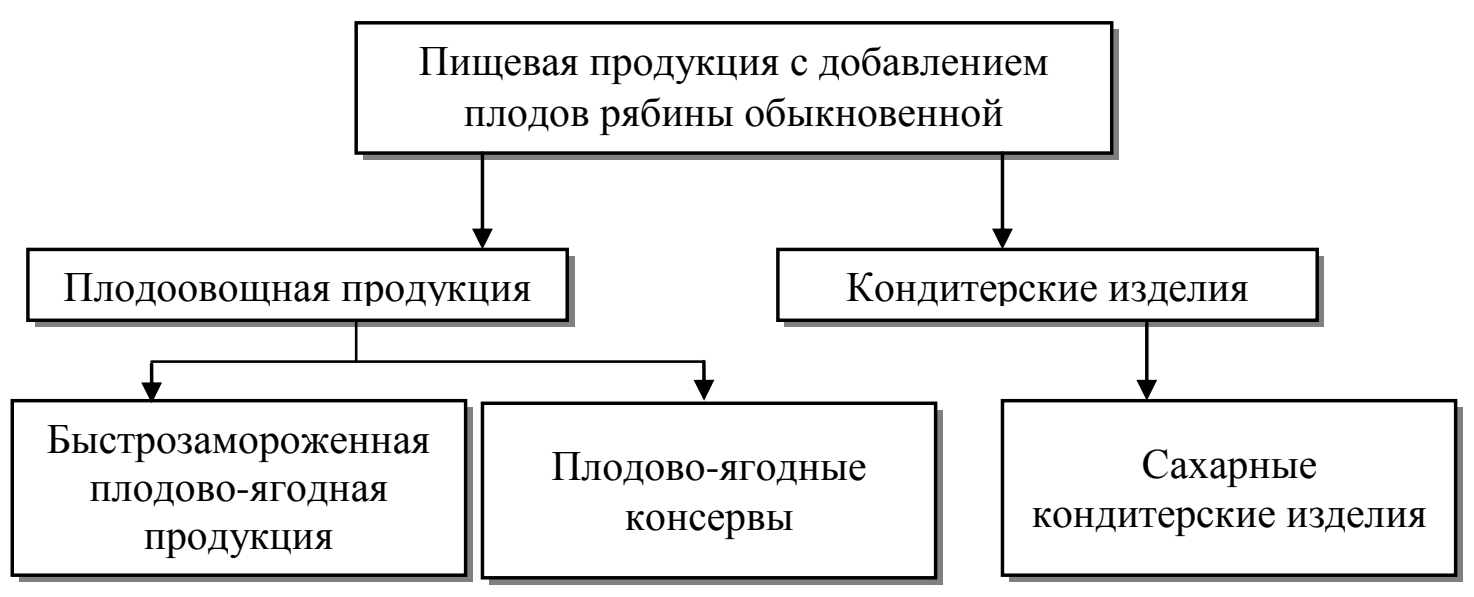

Рисунок 1. Группы товаров, в которых зарегистрировано присутствие плодов рябины обыкновенной (сибирской)

Figure 1. Groups of goods in which the presence of common fruits of Sorbus Sibirica hedl. is registered

Замороженные плоды рябины обыкновенной реализуют следующие компании: «Сибирские земли» (г. Новосибирск), «Ягоды Карелии», «ЭкоТаймыр» (ИП Резяпкин Д. В., Россия, Красноярский край). их применяют для производства шоколада (ТМ «Таежный вкус», г. Томск), шоколада с добавкой экстракта или плодов рябины обыкновенной компании Sweetexim (г.Москва). Кроме вышеперечисленного, на территории Российской Федерации осуществляется производство и реализация варенья «Варенье рябиновое с корицей на кедровом сиропе (ИП Рыльников А. Г., Россия, г.Красноярск), а также поставка сиропа шиповника с рябиной обыкновенной (ОАО «Экзон» Республики Беларусь). Таким образом, с учетом имеющихся литературных данных, к основным приоритетным направлениями для разработки продуктов из плодов рябины следует отнести кисломолочные продукты с наполнителями, мясные полуфабрикаты, полуфабрикаты из мяса птицы, рыбные консервы в маринаде, рыборастительные консервы, сахарные и мучные кондитерские изделия, завтраки сухие, концентраты на плодовых и ягодных экстрактах - кисели, желе, муссы; безалкогольные напитки, плодово-ягодные консервы.

Требования технологии изготовления определяются направлением полученного товара:

- при желании сохранения в готовом продукте витамина С следует использовать щадящие (не более $60{ }^{\circ} \mathrm{C}$ ) режимы термообработки;

- для достижения максимальной степени усвоения $\beta$-каротина, являющегося жирорастворимым соединением, следует вводить в продукты жировую компоненту.

Состав продуктов определяет и условиях их упаковки: для предотвращения процессов окисления и разложения $\beta$-каротина желательно упаковывать продукты в стеклянные емкости темного цвета, допускается также использование непрозрачной бумаги, фольгированной упаковки, пластика и др. 
Поскольку главное преимущество дикорастущих плодов в их природном происхождении и произрастании на территориях экологически чистой арктической зоны Красноярского края (без существенного антропогенного воздействия на окружающую среду) данную продукцию можно отнести к органической и, следовательно, маркировать ее на этикетках «органик» [37]. В настоящее время на территории Российской Федерации действует ГОСТ 33980-2016 «Продукция органического производства», который, к сожалению, не распространяется на дикорастущее сырье и продукты из него. Следовательно, актуальна проблема сертификации дикоросов.

Существенный объем плодов рябины собирают и реализуют в частном порядке, фактически в настоящее время нелегализованный рынок дикоросов в несколько раз превышает объем официального. Так, в работе Ю.Г. Бендерского с соавт. [38] экономическая оценка потенциала дикорастущих ягод (на примере брусники, клюквы, черники и голубики) составляет по Туруханскому району 0 т, при этом фактическое использование - 60 т. Для вывода рынка дикоросов из «тени» следует:

- упростить процедуру права аренды лесного участка, используемого для заготовки плодового сырья в коммерческих целях; допустить варьирование срока аренды в более широких пределах (в настоящее время срок составляет 10 лет), провести оценку возможных объемов изъятия природных ресурсов с целью предотвращения негативного влияния на растительный мир и нарушения экосистем;

- организовать пункты приема дикорастущего (и культивируемого - поскольку рябина обыкновенная является зимостойким растением, возможно ее культивирование в условиях Крайне Севера) у населения путем закупки объектов непосредственно в местах их сбора для предотвращения порчи плодово-ягодного сырья при неправильно организованной транспортировке; сбора;

- организовать глубокую переработку плодово-ягодного сырья вблизи места

- вести подготовку квалифицированных кадров, способных организовать комплексную переработку растительного сырья;

- разработать комплексные схемы переработки плодово-ягодного сырья (вариант представлен на рис. 2).

Рассмотрим основные достоинства и недостатки предложенной схемы комплексной переработки плодов рябины сибирской (табл. 3).

Таблица 3. Основные достоинства и недостатки предлагаемой схемы комплексной переработки рябины сибирской

Table 3. The main advantages and disadvantages of the proposed scheme of complex processing of fruits of Sorbus Sibirica Hedl.

\begin{tabular}{|l|l|}
\hline \multicolumn{1}{|c|}{ Достоинства } & Недостатки \\
\hline \multicolumn{1}{|c|}{ Расширение ассортимента продукции. } & Усложнение производственных и \\
Возможность реализации переработки по & сбытовых процессов. \\
данной схеме других видов плодово- & Повышение требований к \\
ягодного сырья/снижение риска от потерь & квалификации сотрудников. \\
при неурожае одного вида. & Рост стоимости продукции глубокой \\
Расширение сезона работы за счет как & переработки сырья \\
использования сырья, собираемого в разные & \\
сроки, так и последующей глубокой & \\
переработки первично обработанного сырья. & \\
Увеличения коэффициента загрузки & \\
предлагаемых мощностей & \\
\hline
\end{tabular}




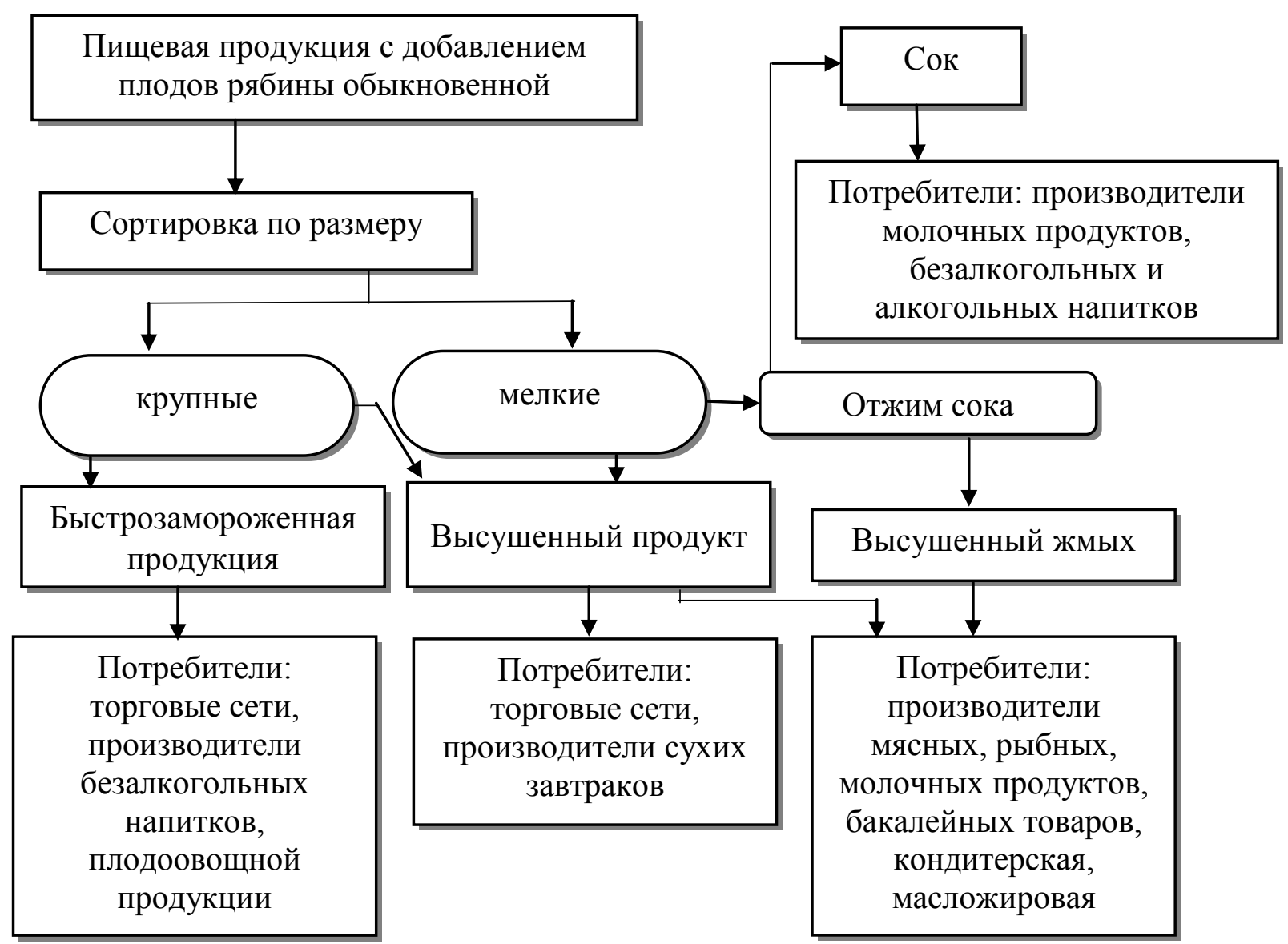

Рисунок 2. Предложения по комплексной переработке плодов рябины сибирской

Figure 2. Proposals for the complex processing of fruits of Sorbus Sibirica Hedl.

Уровень безработицы среди населения, проживающего в районах Крайнего Севера Красноярского края достаточно высок, и организация системы закупок будет способствовать заинтересованности населения заниматься сбором дикоросов. Кроме того, в последнее время зарегистрирована тенденция к увеличению потребления натуральных экологических продуктов, которые используются в качестве красителей, вкусовых и ароматических заменителей как в мире, так и в регионах Российской Федерации, характеризующихся высокой платежеспособностью населения. Таким образом, организация массового сбора и промышленной переработки дикоросов в Красноярском крае может оказаться весьма выгодным и высокорентабельным бизнесом.

Выводы и дискуссионные вопросы. На основании проведенных исследований отметим несколько моментов.

1. Использование плодов рябины сибирской при производстве пищевых продуктов способно повысить потребление населением как витаминов (витамин С, каротиноиды), углеводов (в частности, пищевых волокон), флавоноидов, так и минеральных веществ.

2. Несмотря на наличие широкого спектра исследований, посвященных использованию плодов рябины обыкновенной и продуктов их переработки в производстве пищевых продуктов, фиксируется отсутствие подобного рода товаров в торговых сетях. В то же время приоритетными направлениями разработки продуктов из плодов рябины являются кисломолочные продукты с наполнителями, мясные 
полуфабрикаты, полуфабрикаты из мяса птицы, рыбные консервы в маринаде, рыборастительные консервы, сахарные и мучные кондитерские изделия, завтраки сухие, концентраты на плодовых и ягодных экстрактах - кисели, желе, муссы; безалкогольные напитки, плодово-ягодные консервы.

3. Организация на территориях Красноярского края система сбора, реализации и предварительной переработки плодов рябины сибирской будет способствовать повышению уровня жизни населения как вследствие организации дополнительного источника доходов, так и за счет нормализации рациона питания.

\section{Библиографический список}

1. Егорова, Е.Ю. Продукты функционального назначения и БАД к пище на основе дикорастущего сырья / Е.Ю.Егорова, М.Н.Школьникова // Пищевая промышленность. - 2007. - №11. - С.12-14.

2. Курьянов, М.А. Рябина садовая / М.А. Курьянов. - М.: Сельхозгиз, 1986. $78 \mathrm{c}$.

3. Поплавская, Т.К. Селекция и внедрение новых сортов рябины в садоводство России / Т.К. Поплавская. - Пермь: Перм. книжн. изд-во, 2006. - 152 с.

4. Новрузов, Э.Н. Химический состав плодов дикорастущих плодовых и ягодных растений Азербайджана / Э. Н. Новрузов // Растительные ресурсы. - 1998. №1. - C.48.

5. Деренько, С.А. Каротиноиды плодов Sorbus aucuparia / С.А. Деренько // Химия природных соединений. - 1978. - № 4. - С. 528-529.

6. Минке, О.Э. Углеводный состав дикорастущих и культивируемых ягод Сибири /О.Э. Минке, С.Я. Корячкина, И.В. Сандракова, О.М. Фаттахова // Пищевая промышленность. - 1992. - № 10. - С. 13.

7. Корячкина, С.Я. Минеральный состав дикорастущих и культивируемых ягод Сибири / С.Я.Корячкина, И.В.Сандракова, О.М.Фаттахова // Пищевая промышленность. - 1992. - № 6. - С. 25.

8. Сенченко, Л.К. Минеральный состав плодов красной рябины / Л.К. Сенченко, М.И.Соболева, Г.Д. Селуянева // Изв. вузов, пищ. технол. - 1980. - №4 . - C. 93-95.

9. Первышина, Г.Г. К вопросу миграции макро- и микроэлементов в системе «дикорастущее лекарственное сырья - продукт, содержащий БАВ»/Г.Г.Первышина, Н.Н.Кириенко, А.А.Ефремов, О.В.Гоголева // Материалы III Всероссийской конференции «Новые достижения в химии и химической технологии растительного сырья». Кн.3. - Барнаул: изд-во АГУ, 2007 - С.184-188.

10. Vinson, J. A., Jang Jinhee, Yang Jihong, Sabbagh Yousef, Liang Xiquan, Serry Mamdouh, Proch John, Cai Songhuai. Vitamins and especially flavonoids in common beverages are powerful in vitro antioxidants which enrich lower density lipoporoteins and increase their oxidative resistance after ex vivo spiking in human plasma. / J. A. Vinson, , J. Jang, J. Yang, Yo. Sabbagh, X. Liang, M. Serry, J. Proch, S. Cai // J. Agr. and Food Chem. 1999. - Vol. 47(7). - P. 2502-2504.

11. Kahkonen, M. P. / M. P.Kahkonen, A. I.Hopia, M.Heinonen. Berry phenolics and their antioxidant activity // J. Agr. and Food Chem. - 2001. - 49(8). P. 4076--4082.

12. Pyysalo, H. Phenolic compounds from the berries of Mountain Ash, Sorbus aucuparia / H.Pyysalo, T.Kuusi // S. Food. Sei. - 1974. - 3. - 636638.

13. Hakkinen, S. H. Content of the flavonols quercetin, myricetin, and kaempferol in 25 edible berries / S. H.Hakkinen, S. O.Karenlampi et al. // J. Agr. and Food Chem. - 47(6). -2274-2279. 
14. Речиц, М.А. Содержание в рябине, соке и пюре из нее веществ, обусловливающих горечь и терпкость / М.А. Речиц // Известия вузов: пищевые технологмии. - 1978. - № 4. - С. 35-37.

15. Деренько, С.А. Урсоловая кислота из плодов Sorbus aucuparia / C.А. Деренько, Н.И. Супрунов // Химия природных соединений. - 1979. - №3. - С. $412-413$.

16. Блинникова, О. М. Товароведная оценка плодов рябины обыкновенной как источника ценных микронутриентов при производстве продуктов функционального назначения / О.М.Блинникова // Вестник МичГАУ. - 2013. - № 1. - С. 89-93.

17. МР 2.3.1.0253-21 «Нормы физиологических потребностей в энергии и пищевых веществах для различных групп населения Российской Федерации». - М.: Главное санитарно-эпидемиологическое нормаирование Россйской Федерации. - 72 с. [Электронный pecypc]. URL: https://www.rospotrebnadzor.ru/upload/iblock/789/1.-mr2.3.1.0253_21-normy-pishchevykh-veshchestv.pdf (дата обращения 16.01.2022)

18. Mann, J. I., . Possible implications for health of the different definitions of dietary fibre / J. I. Mann, J. H. Cummings // Nutrition, metabolism and cardiovascular diseases: 2009. - 19. - 226-229.

19. Allen, L. Guidelines on food fortification with micronutrients / L. Allen, C.A.Davis, O. Dary, R.Hurrell // World Health Organization and Food and Agriculture Organization of the United Nations, 341.

20. Hollman, P. H. Dietary flavonoids: intake, health effects and bioavailability P.H.Hollman, M. B.Katan //Food and chemical. - 1999. -37 (9-10). - 937-942.

21. Носова, Л.Н. Исследование и разработка технологии производства сливочного масла с продуктами переработки рябины : автореф. дис. ... техн. наук : 05.18 .04 / Носова Лариса Николаевна. - Кемерово, 2002. - 25 c.

22. Беляев, А.Г. Изучение возможности использования рябины обыкновенной и рябины черноплодной при изготовлении йогуртов / А.Г.Беляев, С.Г.Боев, Н.С.Бароян // Технологии пищевой и перерабатывающей промышленности АПК - продукты здорового питания. - 2019. - №4. - С.15-21.

23. Мартынова, Е.Г. Использование технологии инкапсуляции порошка рябины для усовершенствования рецептур творожных десертов функционального назначения/ Е.Г.Мартынова, И.В.Мацейчик, И.О.Ломовский // Пищевая промышленность. - 2018. №11. - С.20-24.

24. Волхонская, М.С. Технологическая схема производства мясных полуфабрикатов под маринадом на основе плодов рябины обыкновенной / М.С. Волхонская, Г.Г. Первышина, Т.Л. Камоза // Современная наука и инновации. - 2017. No 2 (18). - C. 134-140.

25. Масло салатное: пат. 2092070 Рос. Федерация. № 95118070/13 / Ключкин В.В., Мартыненко Ф.К., Лобаев Н.В., Скоблилов А.И.; заявл. 23.01 .95 ; опубл. 10.10.97, Бюл. № 28. 4 с.

26. Сеит-Абдаева, С. К. Применение ягодного сырья в производстве десертных майонезов / С.К.Сеит-Абдаева, М.А. Субботина, С.Н. Макеева // Проблемы и перспективы здорового питания: Сб. науч. работ. - Кемерово, 2000. - С. 84.

27. Корчагин, В. И. Разработка подхода к выбору полифункциональных добавок в производстве хлебобулочных и мучных кондитерских изделий /В.И. Корчагин, Н.М.Дерканосова, Ю.С.Сербулов // Хранение и переработка сельхозсырья. - 1999. №8. - С. 27-29.

28. Тамазова, С.Ю. Пищевые добавки на основе растительного сырья, применяемые в производстве хлебобулочных и мучных кондитерских изделий/ С.Ю.Тамазова, В.В.Лисовой, Т.В.Першакова, М.А.Казимирова // Политематический 
сетевой электронный научный журнал Кубанского государственного аграрного университета. - 2016. - №122(08) - 18 с. - [Электронный ресурс]. URL: http://ej.kubagro.ru/2016/08/pdf/76.pdf (дата обращения 16.01.2022)

29. Способ производства пряников: пат. 2163073 Рос. Федерация. N 2000107415/13 / Деулин С.Ю., Чуйкова И.И.; з Заявл. 27.03.2000; опубл. 20.02.2001 [Электронный ресурc]. URL: https://findpatent.ru/patent/216/2163073.html (дата обращения 16.01.2022)

30. Мацейчик, И.В. Влияние добавок из ИК-сушенного растительного сырья на качество печенья / И.В.Мацейчик, А.А.Красильникова, С.К.Волончук // Пища. Экология. Качество: Сб. мат. 2 Междунар. науч.-практ. конф. - Новосибирск, 2002. - С. 281-285.

31. Корячкина, С.Я. Способ повышения биологической ценности макаронных изделий из хлебопекарной муки / С.Я.Корячкина, Г.А.Осипова // Хлебопечение России. -2002 . - № 6. - С. 15-17.

32. Витаминный чайный сбор "Рябиновый" из лекарственных растений: пат.2045274 Рос. Федерация № 5047243/4 / Е.Д.Гольдберг, А.М.Диган, Н.И. Суслов, А.И. Потапов; заявлено 08.05.92; опубл. 10.10.95, бюл. № 28. 3с.

33. Маюрникова, Л. А. Применение экстрактов растительного сырья в качестве биологически активных добавок / Л. А. Маюрникова, Г. А. Гореликова, В. М. Поздняковский, С. К. Щипицын // Пищевые ингредиенты: сырье и добавки. - 1999. - № 2. - C. 50.

34. Композиция ингредиентов для тонизирующей ароматической добавки «Звезда Байкала»: пат.2215433 Рос. Федерация № 98105936/13/ Лазарева Л.В.; заявл. 26.03.1998 ; опубл. 10.11.2003 - - [Электронный ресурc]. URL: https://elibrary.ru/download/elibrary_37919914_27389657.pdf (дата обращения 16.01.2022)

35. Способ получения конфитюра: пат. 2171041 Рос. Федерация № 99117082/13 / Иванова Т. Н., Седов Ю. А., Житникова В. С.; Орлов, гос. техн. ун-т.; заявл. 04.08.1999; опубл. 27.07.2001. - [Электронный ресурс]. URL: https://patentdb.ru/patent/2171041 (дата обращения 16.01.2022)

36. Способ производства желейного мармелада: пат. 2127985 Рос. Федерация № 96121303/13 / Корячкина С. Я.; заявл. 30.10.1996; опубл. 27.03.1999, Бюл. № 9. - 5 с.

37. Горбатов, А. В. Развитие рынка органической продукции в России / А. В. Горбатов// Фундаментальные исследования. - 2016. - № 11-1. - С. 154-158.

38. Бендерский Ю.Г. Теоретические и практические аспекты экономической оценки биоресурсного потенциала Красноярского края / Ю.Г.Бендерский, И.В.Варфоломеев, А.П.Лопатин, В.Д.Петренко// Красноярск: Красноярский филиал Госцентра «Природа». - 2002. - 95 с.

\section{References}

1. Egorova, E.Yu., Shkolnikova M.N. (2007). Functional purpose products and dietary supplements for food based on wild-growing raw materials. Food industry, 11, 12-14

2. Kuryanov, M.A. (1986) Ryabina sadovaya .M.: Selkhozgiz, 78

3. Poplavskaya, T.K. (2006). Selection and introduction of new varieties of rowan in horticulture in Russia. Perm: Perm. book. publishing house, 152

4. Novruzov, E. N. (1998). Chemical composition of fruits of wild fruit and berry plants of Azerbaijan . Plant resources, 1, 48.

5. Derenko, S. A. (1978)/ Carotenoids fruits of Sorbus aucuparia/ Chemistry of natural compounds, 4, 528 - 529.

6. Mink, O. E., Karachkina, S.Y., Sandrakov, I.V., Fattakhova, O.M. (1992)/ Carbohydrate composition of wild and cultivated berries Siberia/ Food industry, 10. 13. 
7. Karachkina, S. Y., Sandrakova, I.V., Fattakhova, O.M. (1992). Mineral composition of wild and cultivated berries VBof Siberia. Food industry, 6,25.

8. Senchenko, L. K., Sobolev, M.I., Seluanov, G.D. (1980). The Mineral composition of the fruit are red ash, Izv. universities, food. tekhnol 4, 93-95.

9. Pervyshina, G.G., Kirienko, N.N., Efremov, A. A., Gogoleva, O.V. (2007). Migration of macro - and micronutrients in the "wild medicinal raw materials - product containing BAS". Materials of the III All-Russian Conference "New achievements in chemistry and chemical technology of plant raw materials". Book 3. Barnaul: Publishing House of ASU, 184-188

10. Vinson, J.A., Jang J., Yang J., Sabbagh Y., Liang X., Serry M., Proch J., Cai S. (1999). Vitamins and especially flavonoids in common beverages are powerful in vitro antioxidants which enrich lower density lipoporoteins and in-crease their oxidative resistance after ex vivo spiking in human plasma. J. Agr. and Food Chem. 47(7). 2502-2504.

11. Kahkonen, M. P., Hopia, A. I., Heinonen, M. (2001). Berry phenolics and their antioxidant activity. J. Agr. and Food Chem. 49(8). 4076-4082.

12. Pyysalo, H. (1974) Phenolic compounds from the berries of Mountain Ash, Sorbus aucuparia / H.Pyysalo, T.Kuusi. S. Food. Sei. 3. 636 -638.

13. Hakkinen, Sari H., Karenlampi Sirpa O., Heinonen I. Marina, Mykkanen Hannu M., Torronen A. Riitta. Content of the flavonols quercetin, myricetin, and kaempferol in 25 edible berries. J. Agr. and Food Chem. 47(6) 2274-2279.

14. Rechits, M.A. (1978). The content of substances in mountain ash, juice and puree from it that cause bitterness and astringency. Izvestiya vuzov: food tehnologii. 4. 35-37.

15. Derenko, S. A., Suprunov N.A. (1979). Ursolic acid from the fruits of Sorbus aucuparia / S. A. De Renko, N. And. Suprunov. Chemistry of natural compounds. 3. 412-413.

16. Blinnikova, O. M. (2013). Evaluation of the fruits of mountain ash as a source of valuable micronutrients in the production of functional foods. Bulletin of MICHGAU. 1. 8993.

17. MP 2.3.1.0253-21 "Norms of physiological needs for energy and nutrients for various groups of the population of the Russian Federation" - M.: The main sanitary and epidemiological normalization of the Russian Federation. [Electronic source]. Urrl: https://www.rospotrebnadzor.ru/upload/iblock/789/1.-mr-2.3.1.0253_21-normy-pishchevykhveshchestv.pdf (Date of access: 16.01.2022)

18. Mann, J. I., Cummings, J. H. (2009). Possible implications for health of the different definitions of dietary fibre. Nutrition, metabolism and cardiovascular diseases. 19. 226-229

19. Allen, L, Davis, C. A., Dary, O., Hurrell, R. (2006) Guidelines on food fortification with micronutrients. World Health Organization and Food and Agriculture Organization of the United Nations, 341.

20. Hollman, P. H., Katan, M. B. (1999) Dietary flavonoids: intake, health effects and bioavailability. Food and chemical. 37 (9-10)/ 937-942.

21. Nosova, L.N. (2002). Research and development of production technology butter with rowan processing products: abstract. dis. technical sciences: 05.18.04. Kemerovo. $25 \mathrm{p}$.

22. Belyaev, A.G., Boev S.G., Baroyan, N.S. (2019). The study of the possibility of using mountain ash and mountain ash in the manufacture of yoghurts. Technologies of the food and processing industry of the agro-industrial complex - healthy food products. 4. 15-21.

23. Martynova, E.G., Maciejczyk I.V, Lomovsky I.O (2018). The use of rowan powder encapsulation technology to improve the recipes of curd desserts for functional purposes. Food industry. 11. 20-24. 
24. Volkhonskaya, M.S., Pervyshina G.G., Kamoza T.L. (2017). Technological scheme of production of meat semi-finished products under marinade based on the fruits of mountain ash. Modern science and innovation. 2 (18). 134-140.

25. Salad oil: pat. 2092070 Ros. Federation. No 95118070/13 / Klyuchkin V.V., Martynenko F.K., Lobaev N.V., Skoblilov A.I.; application 23.01.95 ; publ. 10.10.97, Bul. No. 28.4 p.

26. Seit-Abdayeva, S. K., Subbotina M. A., Makeeva S. N. (2000). The use of berry raw materials in the production of dessert mayonnaise. Problems and prospects of healthy nutrition: Collection of scientific works. 2000. 84.

27. Korchagin, V. I., Derkanosova N. M., Serbulov Y. S. (1999). Development of an approach to the selection of multifunctional additives in the production of bakery and flour confectionery products. Storage and processing of agricultural raw materials. 8. 27-29.

28. Tamazova, S.Yu., Lisovoy V.V., Pershakova T.V., Kazimirova M.A.(2016). Food additives based on vegetable raw materials used in the production of bakery and flour confectionery products. Polythematic online electronic scientific journal of the Kuban State Agrarian University, 122(08), 18 [Electronic source]. Urrl: http://ej.kubagro.ru/2016/08/pdf/76.pdf (Date of access: 16.01.2022)

29. The method of production of gingerbread: pat. 2163073 Grew. Federation. N 2000107415/13 / Deulin S.Yu., Chuikova I.I.; z Application. 27.03.2000; publ. 20.02.2001 [Electronic resource]. Urrl: https://findpatent.ru/patent/216/2163073.html (Date of access: 16.01.2022)

30. Maciejczyk, I.V., Krasilnikova A.A., Volonchuk S.K. (2002). The effect of additives from IR-dried vegetable raw materials on the quality of cookies. Food. Ecology. Quality: Sat. mat. 2 International Scientific and Practical Conference, Novosibirsk, 281-285.

31. Koryachkina, S.Ya., Osipova G.A. (2002) A way to increase the biological value of pasta from baking flour. Bakery of Russia. 6. 15-17.

32. Vitamin tea collection "Rowan" from medicinal plants: pat.2045274 Ros. Federation No. 5047243/4 / E.D. Goldberg, A.M. Digan, N.I. Suslov, A.I. Potapov; announced 08.05.92; publ. 10.10.95, bul. No. 28. 3c.

33. Mayurnikova, L. A., Gorelikova G. A., Pozdnyakovsky V. M., Shchipitsyn S. K. (1999). The use of extracts of plant raw materials as biologically active additives. Food ingredients: raw materials and additives, 2, 50.

34. Composition of ingredients for the tonic aromatic additive "Baikal Star": pat.2215433 Ros. Federation No. 98105936/13/ Lazareva L.V.; application 26.03.1998 ; publ. 10.11.2003 - [Electronic source]. URL: https://elibrary.ru/download/elibrary_37919914_27389657.pdf (Date of accesse: 16.01.2022)

35. The method of obtaining confiture: pat. 2171041 Ros. Federation No. 99117082/13 / Ivanova T. N., Sedov Yu. A., Zhitnikova V. S.; Orlov, State Technical University. un-T.; application 04.08.1999; publ. 27.07.2001. - [Electronic source]. Urrl: https://patentdb.ru/patent/2171041 (Date of c access: 16.01.2022)

36. Method of production of jelly marmalade: pat. 2127985 Ros. Federation No. 96121303/13 / Koryachkina S. Ya.; application 30.10.1996; publ. 27.03.1999, Bul. No. 9 - 5 p.

37. Gorbatov, A.V. (2016) Development of the market of organic products in Russia. Fundamental research, 11-1, 154-158.

38. Bendersky, Yu.G., Varfolomeev I.V., Lopatin A.P., Petrenko V.D. (2002). Theoretical and practical aspects of the economic assessment of the bioresource potential of the Krasnoyarsk Territory. Krasnoyarsk: Krasnoyarsk branch of the State Center "Nature", 95 p. 